\title{
La forma original del Cubete del Alcázar Real de Carmona
}

\author{
The original shape of the Cubete of the Alcazar of Carmona
}

\section{Antonio Almagro Gorbea}

Real Academia de Bellas Artes de San Fernando, Madrid, Spain, aalmagro@cica.es

\begin{abstract}
Among the works of the so-called "transitional" military architecture from the last quarter of the fifteenth century, one of the most unique cases erected in the Iberian Peninsula is the Cubete of Carmona (Seville). This bastion built in the times of the Catholic Monarchs follows the new poliorcetic standards, but with forms, which are quite innovative and could be considered breakthrough. Conceived as a bastion external to the Alcázar Real, it has a moat in part connected with the moat of the main fortress. The bastion is open in the rear, and could be consider a ravelin, although its location is in an angle of the outer enclosure of the Alcazar, which preludes the subsequent pentagonal bastions. Its anomalous plan is a horseshoe shape that has been discussed by various authors, but so far, there has never been a fully detailed survey with elevations and sections, nor, above all, an attempt to address their hypothetical reconstruction. This paper presents new plans, sections, elevations and images that proves this work is unusual and truly revolutionary for its time.
\end{abstract}

Keywords: Artillery bastion, transition fortification, torus-shaped parapet.

\section{Introducción}

El llamado Alcázar de Arriba o Alcázar Real es la mayor y más importante de las fortalezas con que contaba la ciudad de Carmona durante la Edad Media (Almagro y Maier, 2014). Ocupa la zona más alta del cabezo o meseta sobre la que se asienta la población en el extremo oriental de la misma. Mientras hacia occidente y el norte la pendiente del terreno es suave, hacia el oeste y el sur la meseta presenta un brusco desnivel que proporciona una buena defensa natural a ese lugar. Este conjunto se compone de dos recintos, uno interno compuesto por estructuras defensivas y residenciales, que se sitúa en la zona más elevada y otro externo que engloba al interior por tres de sus lados. La forma general del conjunto es rectangular, orientado con sus lados más largos en la dirección norte-sur. Por el lado oriental el recinto externo no rodea al principal pues éste se arrima al cortado abrupto que tiene la meseta en ese lugar (Fig. 1).

El recinto externo, del que ha desaparecido todo el sector sureste por la construcción del Parador Nacional de Turismo, parece obra casi toda ella de un mismo momento que en principio podemos atribuir al reinado de Pedro I a juzgar por los escasos elementos ornamentales que aparecen en su puerta de entrada. Este recinto está formado por una muralla construida con un zócalo de mampostería bastante elevado en el que se abren numerosas saeteras y una zona alta de obra de tapia con su correspondiente peto y almenas hechos con la misma técnica. La muralla que sólo se ha conservado en sus lados norte y oeste carecía prácticamente de torres de flanqueo, salvo en su extremo meridional, en donde se sitúan la puerta principal, que forma un ligero 
saliente, y dos torres, una semicircular y otra cuadrada situada ésta última en el ángulo suroeste. Al norte de la puerta se extiende una cortina casi rectilínea de $127 \mathrm{~m}$ de longitud hasta el ángulo noroeste, toda ella sin torres ni elementos singulares de defensa. En el lado norte, otro lienzo igualmente sin torres de $93 \mathrm{~m}$ cierra el recinto.

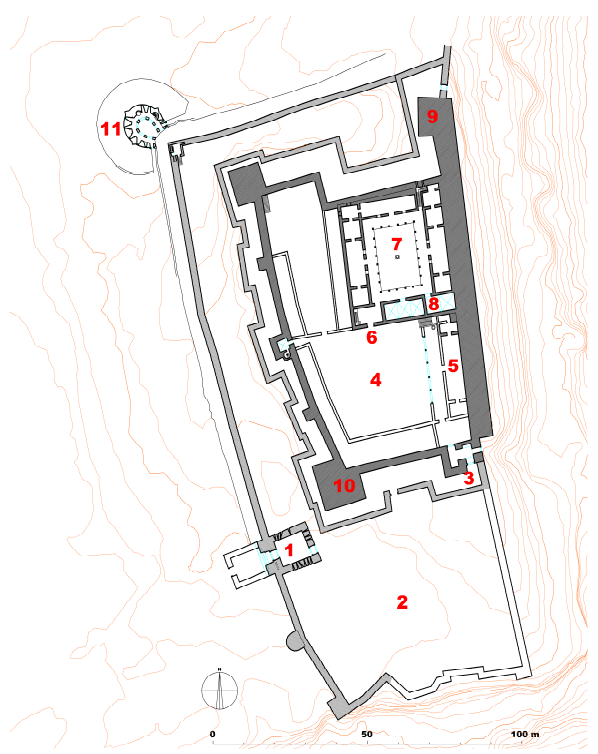

Fig. 1. Planta del Alcázar de Carmona con la ubicación del Cubete $\left(n^{\circ} 11\right)$.

La esquina noroeste presenta una solución algo anómala que seguramente no corresponde a la inicial de tiempos de Pedro I ya que lo lógico hubiera sido que en el ángulo se dispusiera una torre sobresaliente que flanqueara ambas cortinas. La esquina actual está formada por un ángulo prácticamente recto hecho de cantería en toda su altura, cantería que se extiende en ambos paños durante un amplio trecho sin que se aprecie más solución de continuidad que las juntas limpias entre la cantería y la tapia que conforma la casi totalidad de los muros.

Para refuerzo de este ángulo se dispuso en un momento posterior que como veremos pudo ser las últimas décadas del siglo $\mathrm{XV}$, un baluarte artillero que ha sido objeto de la atención de numerosos investigadores por la originalidad de sus formas. En la planta dibujada por el arqueó- logo inglés G. Bonsor en 1886 para la historia de Carmona de Manuel Fernández López (Fernández, 1886), dibuja de manera incipiente una planta de este baluarte que rotula como "el $\mathrm{Cu}$ bete". Los primeros planos con calidad métrica y analítica de esta obra arquitectónica los realizó Alfonso Jiménez Martín incluyéndolos en la publicación de su tesis doctoral sobre la Puerta de Sevilla en Carmona (Jiménez, 1989), (Fig. 4). Dichos planos, que sólo incluyen una planta baja y otra alta, han sido reutilizados por otros autores, sin aportar nada nuevo a su descripción gráfica (Mora Figueroa, 1997, Fig. 6; Cobos, 2004, Fig. 15). Las referencias a esta singular construcción han sido numerosas, pero sin completar un levantamiento integral que incluyera alzados y secciones, a nuestro entender fundamentales para describirla y analizarla adecuadamente. Presentamos aquí un levantamiento completo del baluarte que nos ha servido para plantear las hipótesis sobre su forma original. ${ }^{1}$

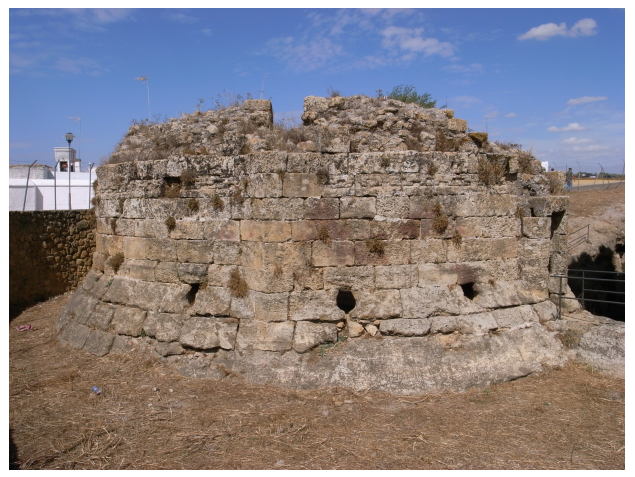

Fig. 2. Vista del Cubete desde el suroeste.

Este baluarte artillero constituye una de las piezas de arquitectura militar del periodo de transición a las armas de fuego más interesantes de toda la Península y es citado siempre como el Cubete (Fig. 2). Tiene planta ovoide de herradura al encontrarse abierto por la gola para impedir que, caso de ser ocupado por los asaltantes, pudiera ser usado como posición de ataque a la fortaleza (Fig. 3). El reducto se encuentra separado del recinto exterior por un foso excavado en la roca que corre a lo largo de las murallas norte y oeste, a plomo de las mismas, y cuya apertura podría corresponder al momento de construcción del baluarte. En este punto el foso se abrió por 
donde quizás estuvo la supuesta torre de ángulo, aunque en la base de los paramentos no se llegue a distinguir una clara discontinuidad de las fábricas que permita dar mayor verosimilitud a esta hipótesis. Junto con la apertura del foso y la construcción del cubo artillero se transformaron en troneras de orbe y palo muchas de las saeteras abiertas en la parte baja de la muralla practicando orificios circulares en la parte inferior de la hendidura y agrandando el hueco hacia el interior para formar pequeñas cámaras de tiro que ni siquiera se conformaron con jambas y arcos.

La supuesta torre del ángulo pudo haber sido sustituida por la actual torre que por el exterior
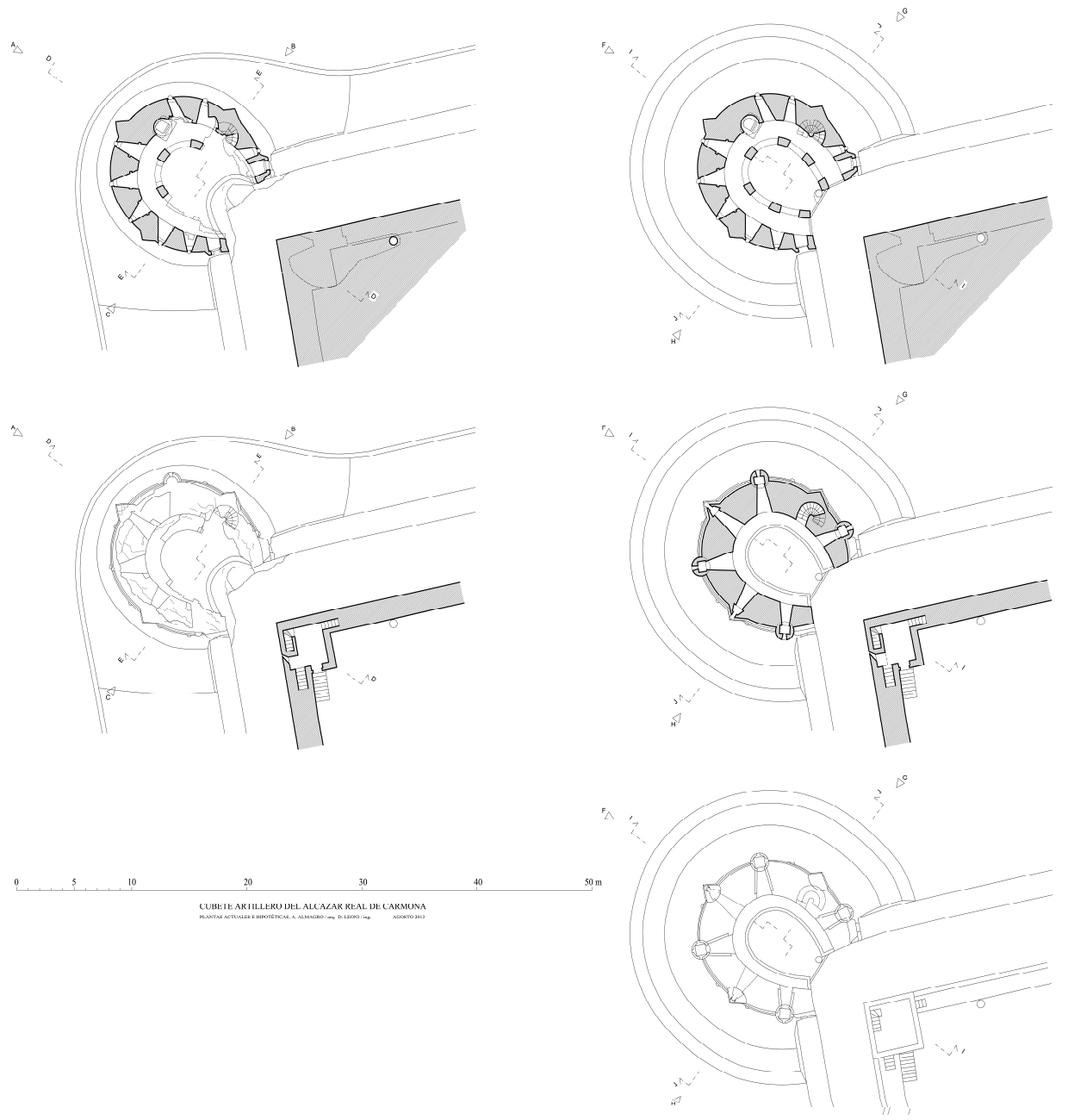

Fig. 4. Plantas actuales e hipotéticas del Cubete de Carmona. 
con las fábricas contiguas de tapia, aunque sí parece tenerla en la base de mampostería. Esta torre, en su interior, alberga una pequeña habitación con acceso por el lado sur mediante una escalera adosada a la muralla oeste. Del interior de la habitación, hoy parcialmente arruinada y que se cubría con bóveda vaída hecha de ladrillo, arrancan otras tres escaleras, dos para subir a los adarves de las murallas adyacentes y otra para llegar a la terraza, alojadas todas en el espesor de los muros. En el arranque de la escalera del lado oeste hay una pequeña cámara de tiro con una aspillera dirigida hacia el Cubete que se complementaba con una tronera circular abierta en el mismo ángulo de la torre y con la misma orientación (Fig. 4).

\section{Descripción}

El baluarte artillero construido fuera del recinto tiene planta con perfil exterior con forma de herradura ovalada cuyo eje sigue aproximadamente la dirección de la bisectriz del ángulo noroeste del recinto exterior del alcázar. El óvalo lo determinan dos circunferencias de $6,25 \mathrm{~m}$ de radio con centros separados apenas $1,15 \mathrm{~m}$. Sin embargo, el perfil interno del muro tiene forma ovoide lo que produce una progresiva disminución de su espesor que va de los $2,50 \mathrm{~m}$ en el frente a apenas 1,2 $\mathrm{m}$ en los extremos de la herradura. El muro se refuerza por el exterior mediante tres espolones de forma triangular mientras por el interior se desarrolla una galería abovedada apoyada en el muro y en una sencilla arquería de pilastras lisas y arcos rebajados (Fig. 5).

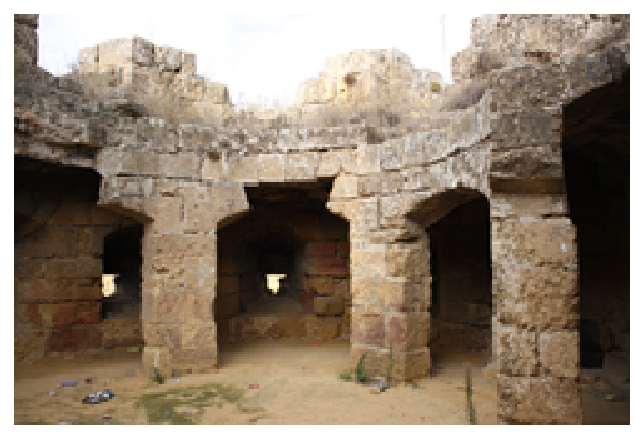

Fig. 5. Vista del interior del Cubete.

Hasta ocho troneras con sus correspondientes cámaras de tiro perforan el muro con una distri- bución bastante irregular ya que hacia el oeste y sur apuntan cinco frente a solo tres que miran al norte. Esta anomalía se debe a la presencia de un pozo y de la escalera de subida al adarve superior. El pozo, ubicado casi en el frente del baluarte y hoy prácticamente enrunado, tiene su boca en gran parte bajo el muro exterior que presenta un nicho para cobijarlo ${ }^{2}$. La escalera se aloja también dentro del espesor del muro y tiene disposición de caracol. En los dos extremos de la herradura hay dos poternas de apenas 0,80 $\mathrm{m}$ de ancho que servían para acceder al bastión desde el exterior. Dentro del bastión queda un patio de planta ovoide de 4,70 m de anchura máxima por $6,70 \mathrm{~m}$ de longitud, que tiene uno de sus lados abierto hacia el foso y la torre de ángulo de la fortaleza.

El baluarte artillero posee un foso semicircular (Figs. 6 y 7) hoy en gran parte soterrado e invadido por un camino moderno, que se excavó todo él en la roca. Este foso está separado del que circunda la muralla por dos muros hechos con la misma roca tallada, por cuyo coronamiento se accede a las dos poternas que permiten entrar al interior del bastión.

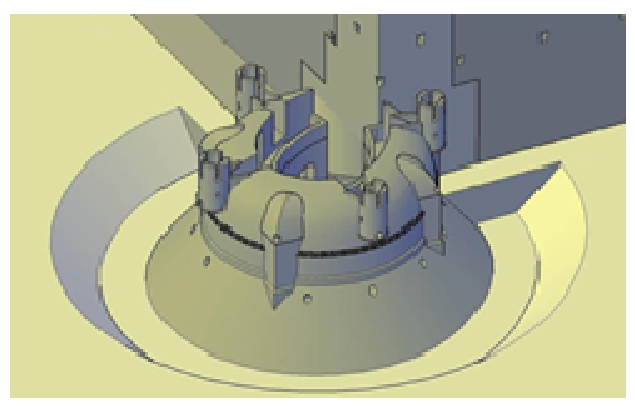

Fig. 6. Hipótesis de la forma original del Cubete.

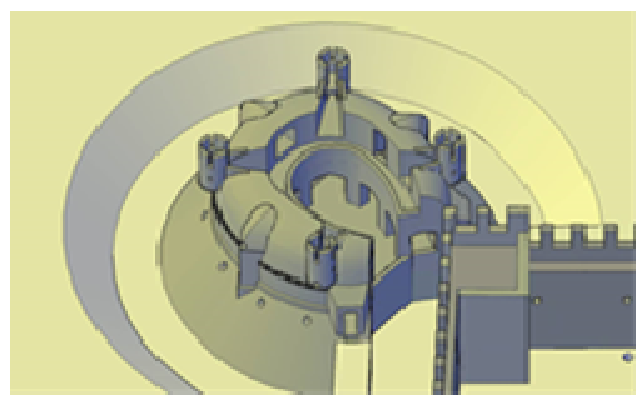

Fig. 7. Hipótesis de la forma original del Cubete. 


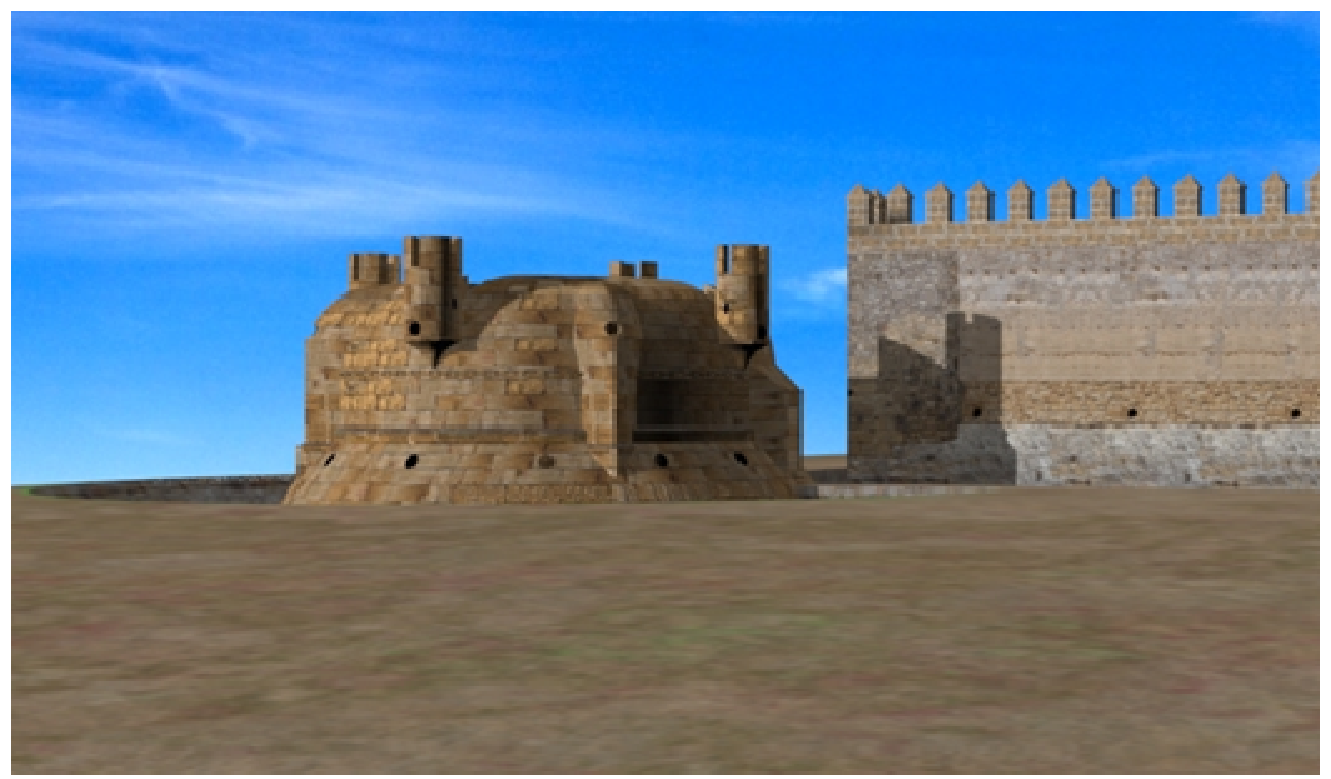

Fig. 8. Imagen virtual hipotética de la forma original del Cubete de Carmona.

Toda esta disposición nos permite sostener que la obra del reducto artillero y de los fosos es toda contemporánea y posterior a la construcción del recinto exterior del alcázar. Debemos también indicar que según todos los indicios existió una comunicación entre el baluarte exterior y la fortaleza a través de un pozo, situado dentro de ésta, cuya boca superior está hoy cegada, por el que se bajaba a una oquedad existente en la roca bajo la fortaleza principal, quizás restos de un antiguo silo o cisterna, que permitía acceder al fondo del foso. No se ve hoy ningún indicio que permita suponer la presencia de una obra de fábrica en el fondo de éste para atravesarlo con protección, a modo de caponera, pero en todo caso, a través del foso se podría llegar al abrigo de disparos enemigos hasta la gola del baluarte por donde se subiría al patio interior del cubo artillero.

El alzado exterior del baluarte presenta tres zonas bien diferenciadas. Una inferior con forma de escarpa o alambor que hoy apenas aparece visible en una altura de $1,70 \mathrm{~m}$ pero que podemos suponer que llegará a los 4,00 y 4,50 m contando la zona enterrada. Por encima del alambor hay una zona vertical de $2,15 \mathrm{~m}$ de altura que presenta un retalle inferior y remata en un cordón con forma de cadena que corre horizontal a lo largo de todo el muro y que sólo queda interrumpida por los espolones triangulares antes citados. En la parte superior de la escarpa se abren con forma circular las troneras de la planta baja, de modo que podían permitir tiros rasantes sobre el terreno circundante ya que se encuentran ligeramente más altas que éste. A partir de este punto se desarrolla el parapeto que presenta perfil en bocel de más de 2,50 m de radio. Mientras los espolones se remataban un poco más arriba del cordón de cadena con una forma de diedro alabeado, de ese mismo cordón surgen cuatro ménsulas de planta circular de 1,60 m de diámetro y que seguramente fueron la base de sendas torrecillas o escaraguaitas, de las que desgraciadamente no quedan más que sus arranques.

El adarve superior está bastante destruido pero los restos conservados, recogidos en los dibujos del levantamiento, permiten dibujar la hipótesis que planteamos. El adarve, que corre a lo largo del muro sobre la mitad de la galería inferior, queda defendido por el parapeto abocelado que debía alcanzar una altura de unos 2,65 $\mathrm{m}$ y que cubre la otra mitad de la citada galería. Dada la altura de este parapeto, las torrecillas externas mencionadas debían permitir la vigilancia de la base del baluarte y del foso, haciendo la misma función que desempeñarán las garitas colocadas 

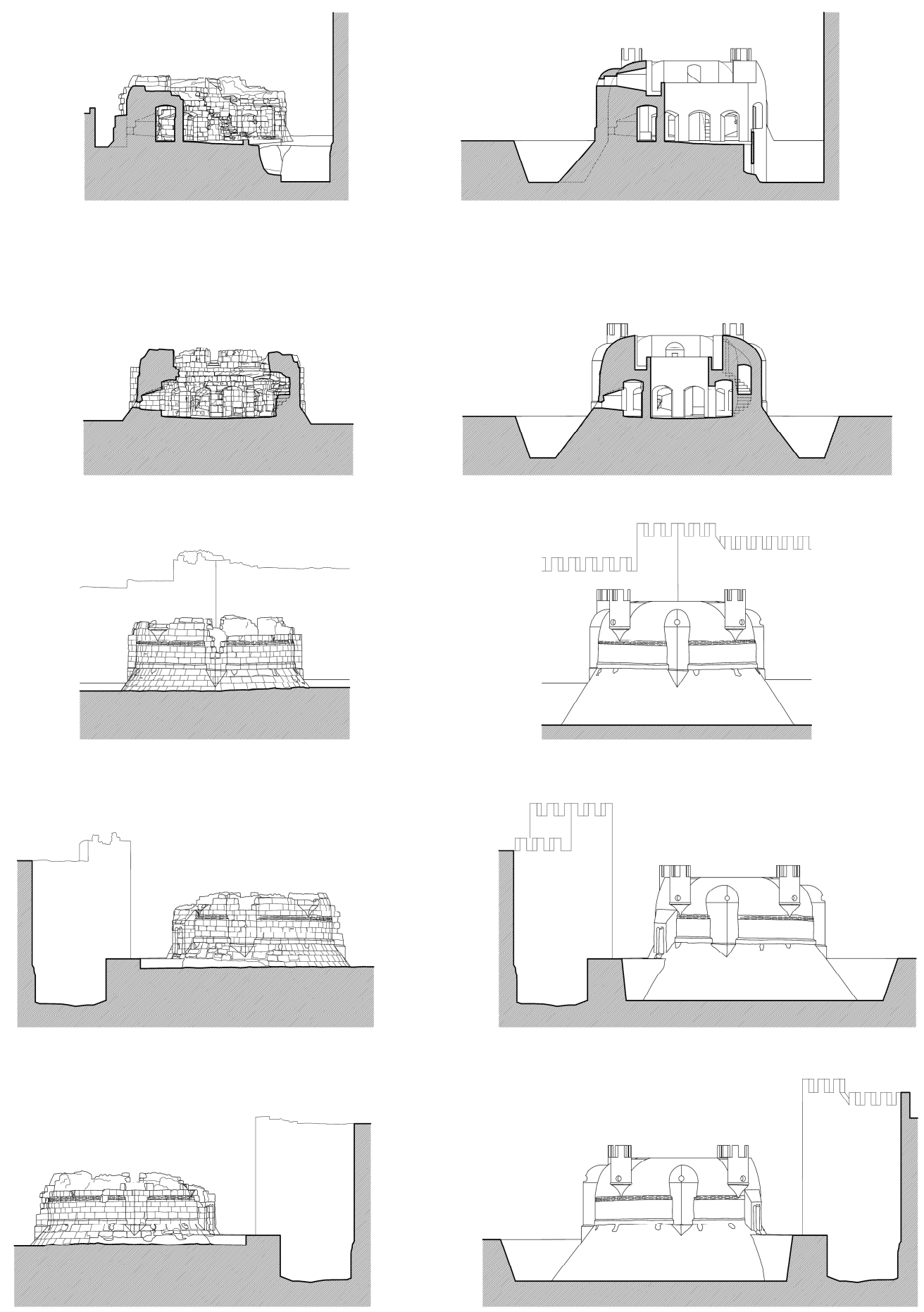

$0 \ldots, 5,100$ 30

Fig. 9. Secciones y alzados actuales e hipotéticos del Cubete de Carmona. 
en los vértices de los baluartes de épocas posteriores. El parapeto está atravesado por siete troneras cuyas bocas circulares se abrían en la parte superior de los espolones y en la base de las escaraguaitas. De ambas soluciones existen evidencias. La mejor descripción de esta hipótesis la constituyen los dibujos e imágenes que acompañamos y que muestran el carácter innovador e insólito de esta singular obra (Figs. 4, 6-9).

\section{Datación, autoría y paralelos}

La obra es atribuida a Francisco Ramírez de Madrid, secretario y capitán general de la artillería de los Reyes Católicos. Esta atribución se basa en un documento por el que el 17 de abril de 1486 el secretario real requiere el envío a Carmona de unos picapedreros de la Catedral de Sevilla (Suárez, Mata Carriazo, 1969, p. 540; citado en Jiménez, 1989, p. 67).

Por otro lado, entre 1486 y 1488 se documentan unos "maestros canteros oficiales que andan en la obra del Alcázar Real" que eran forasteros alojados en la villa de Carmona (Catálogo AMC, pp. 85, 99; citado en Jiménez, 1989, p. 67, nota 54 del Cap. 4). La intervención del secretario y artillero en esta obra, en plena guerra de Granada, y cuando además ostentaba el cargo de obrero del Alcázar y las Atarazanas de Sevilla y siendo el responsable de la artillería de los Reyes Católicos durante toda la contienda (Porras, 1996), permite sostener esta hipótesis mientras no exista otra que la contradiga. Es bien sabido que en esta época eran los mismos artilleros los encargados de concebir las nuevas fortificaciones adaptadas al uso de la artillería y su defensa frente a estas armas, en base a su experiencia en la forma de usarlas para destruir las protecciones de plazas y castillos.

La construcción todavía presenta reminiscencias de obra tardogótica como es la decoración de la cadena labrada en la piedra de la sillería que rodea toda la construcción, los dinteles mixtilíneos de las poternas de entrada o la presencia de escaraguaitas, aunque se aprecia su indiscutible concepción para el uso de armas de fuego con troneras y un remate de parapeto abocelado que le confieren una forma absolutamente original e innovadora. Pese a su originalidad, es obra que puede ponerse en relación con otras contemporáneas, tanto por su concepto como por sus formas mostrando el carácter avanzado e innovador de las fortificaciones de ese momento en la corona de Castilla.

La ubicación del cubete artillero está notoriamente pensada no tanto para defenderse de los ataques que pudieran provenir del exterior de la población sino principalmente para controlarla ${ }^{3}$, y es una muestra evidente de la firme voluntad de los Reyes Católicos de hacer respetar su autoridad e imponer su voluntad por encima de la de sus súbditos, con el recurso a las nuevas armas, de las que la corona hizo pronto un eficaz instrumento al servicio de su política.

Este modelo de baluarte exterior de planta redondeada tiene su precedente en el cubete del castillo de Montalbán (Toledo) que podría ser anterior al inicio de la guerra civil castellana. Posteriormente tiene claros seguidores en los revellines y los baluartes externos de ángulo y antepuerta del castillo de Salsas (Rosellón, Francia) obra esta última de Ramiro López, autor también de las fortificaciones de la Alhambra en donde podemos ver otros paralelos en los baluartes de las puertas de la Justicia y de Siete Suelos (Almagro, 2014). El carácter de obra achaparrada, de altura muy inferior a la de la fortaleza principal y abierta por la gola lo encontramos en el baluarte pentagonal del castillo de Trujillo (Almagro, 2016), con el que comparte un cierto aire de modernidad en su forma y aspecto que nos hace recordar a las casamatas y búnkeres del siglo XX. También es de resaltar el parapeto abocelado presente en Trujillo, Salsas y en Berlanga de Duero. Las escaraguaitas son elementos más propios de la arquitectura precedente del siglo $\mathrm{XV}$, aunque aún podemos encontrarlas en Salsas según se representa dicha fortaleza en el cuaderno de dibujos de Francisco de Holanda (Cobos, 2004).

En suma, este Cubete de Carmona combina formas y soluciones presentes en la arquitectura militar castellana de transición, aunque con unos resultados formales realmente sorprendentes e innovadores, que pese a ello parece que no tuvieron en su conjunto una mayor trascendencia 
ya que apenas pueden constatarse en otras obras contemporáneas o posteriores.

\section{Notas}

${ }^{1}$ En 2008 iniciamos un levantamiento completo con medios fotogramétricos que completamos en 2013 con la ayuda de Daniele Leoni, estudiante de la Facultad de Ingeniería de la Universidad de Salerno que realizó una estancia Erasmus en la Escuela de Estudios Árabes del CSIC en Granada para la realización de su tesis de licenciatura.

${ }^{2}$ El agua resultaba un elemento absolutamente esencial en una fortificación con artillería pues era imprescindible para la limpieza y refri- geración de los cañones. Además, la presencia de oscilaciones en su superficie dejada en reposo o la variación de su nivel servía como aviso de posibles labores de zapa o mina en las inmediaciones (Cobos, 2004, pp. 246-250).

${ }^{3}$ Voluntad parecida puede verse en otros casos similares como en el castillo de Trujillo (Almagro, 2016) donde también se levantó un baluarte de antepuerta dirigido hacia la población, y muy especialmente en Granada, donde tras su conquista, una parte considerable de los baluartes que se construyen en la Alhambra y en otros puntos de la ciudad están dirigidos contra la ciudad más que contra el exterior (Bibataubín, Torres Bermejas y Baluarte de la Alcazaba) (Almagro, 2004, p. 213).

\section{Bibliography}

Almagro, A. (2004). Levantamiento arquitectónico, Granada.

Almagro, A. (2016). "El baluarte artillero de transición del castillo de Trujillo", in Gil Crespo, I.J., ed., Actas de las Segundas Jornadas sobre Historia, arquitectura y construcción fortificada, Madrid, pp. 11-26.

Almagro, A.; Maier Allende, J. (2014). "El Alcázar Real de Carmona y su Sala de los Reyes”, in González Jiménez, M.; Caballos Rufino, A.; Ruiz de la Rosa, J.A., eds., Urbanismo, Arquitectura y Patrimonio en Carmona, Sevilla, pp. 279-327.

Cobos, F. (2004), "Los orígenes de la Escuela Española de Fortificación del primer Renacimiento", in Valdés, A., ed., Artillería y Fortificaciones en la Corona de Castilla durante el reinado de Isabel la Católica, 1474-1504, Madrid, pp. 225-267.

Fernández López, M. (1886). Historia de la Ciudad de Carmona, desde los tiempos más remotos hasta el reinado de Carlos I, Sevilla (reedición 1996).

Jiménez, A. (1989). La puerta de Sevilla en Carmona, Sevilla.

Mora Figueroa, L. (1997). "El Alcázar real de Carmona (Sevilla), la muralla exterior y su flanqueo", Archivo Hispalense, T 80, 243-245, pp. 637-652.

Porras Arboledas, P.A. (1996). Francisco Ramírez de Madrid (144?-1501). Primer madrileño al servicio de los Reyes Católicos, Madrid.

Suárez Fernández, L.; Carriazo Arroquia, J. de M. (1969). La España de los Reyes Católicos (1474-1516). Historia de España dirigida por Ramón Menéndez Pidal, Madrid, vol. 17-1. 